\title{
LINEAR DYNAMIC MATHEMATICAL MODEL AND IDENTIFICATION OF MICRO TURBOJET ENGINE FOR TURBOFAN POWER RATIO CONTROL
}

\author{
Khaoula DERBEL (D) ${ }^{1}$, Károly BENEDA (D) 2* \\ 1, 2 Department of Aeronautics, Naval Architecture and Railway Vehicles, \\ Budapest University of Technology and Economics, Müegyetem rkp. 3., H1111 Budapest, Hungary
}

Received 15 December 2018; accepted 27 November 2019

\begin{abstract}
Micro turbojets can be used for propulsion of civilian and military aircraft, consequently their investigation and control is essential. Although these power plants exhibit nonlinear behaviour, their control can be based on linearized mathematical models in a narrow neighbourhood of a selected operating point and can be extended by using robust control laws like $H_{\infty}$ or Linear Quadratic Integrating (LQI). The primary aim of the present paper is to develop a novel parametric linear mathematical model based on state space representation for micro turbojet engines and the thrust parameter being Turbofan Power Ratio (TPR). This parameter is used by recent Rolls-Royce commercial turbofan engines but can be applied for single stream turbojet power plants as well, as it has been proven by the authors previously. An additional goal is to perform the identification for a particular type based on measurements of a real engine. This model has been found suitable for automatic control of the selected engine with respect of TPR, this has been validated by simulations conducted in $\mathrm{MATLAB}^{\star}$ Simulink $^{\star}$ environment using acquired data from transient operational modes.
\end{abstract}

Keywords: gas turbine engine, turbojet, Turbofan Power Ratio, linear mathematical model, state space representation, turbine engine control system, system identification, dynamic simulation.

\section{Introduction}

Micro gas turbine engines have entered several industrial domains throughout the recent decades and their use never stops increasing as stated by do Nascimento et al. (2013). Due to the variety of applications, they can be classified into two main categories. Those used as a developer of shaft power (Bicsák \& Veress, 2017; Seo, Lim, J. Park, M. Park, \& Choi, 2017; Dinc, 2016) and those which act as direct propulsion power plant of different aerial transports and vehicles like sailplanes (Katolicky, Bušov, \& Bartlova, 2014) or engines for drones like the ones detailed by Cwojdziński and Adamski (2014), Dutczak (2016) or Kuz'michev, Tkachenko, Filinov, Krupenich, and Ostapyuk (2017). The main goals of the automatic control of turbojet propulsion engines is to ensure economic operation, enhance flight safety, reduce crew workload of manned systems and extend service life of the entire system as described by Andoga, Főző, Madarász, and Judičák (2010), or expert systems can also implement advanced fault detection and isolation (reported by Nyulászi et al., 2018).
There are two different methods to develop the control system depending on how to acquire the model of the plant to be controlled. The first method is the so-called black-box substitution mentioned by Tavakolpour-Saleh, Nasib, Sepasyan, and Hashemi (2015), which neglects the details of behavior and focuses solely on the system responses. The other one is to create a more or less complex model that is based on physical laws that describe the operation of the plant as noted by Tudosie (2012). In the present work the authors have chosen the latter solution.

This article focuses on a simplified model for those engines, which do not include variable geometry, thus the mathematical model can be significantly reduced. The first section discusses linearized state space representation and special features of the model due to TPR control. In the second section, the authors examine measurement and calculation of thermodynamic parameters used for identification of the particular engine type. The next section considers simulations and validation with measured data. A concluding section closes the article, summarizing the achieved goals and debrief further developments.

*Corresponding author. E-mail: kbeneda@vrht.bme.hu 


\section{Linear dynamic mathematical model of micro turbojet engine}

Figure 1 shows the main aerodynamic stations of the micro turbojet which are important in the present investigation. Station 0 is the static ambient condition; station 1 stands for the compressor inlet, while station 2 is the compressor discharge. Station 3 represents turbine inlet; station 4 is turbine discharge. Station 5 is the exhaust nozzle exit cross-section.

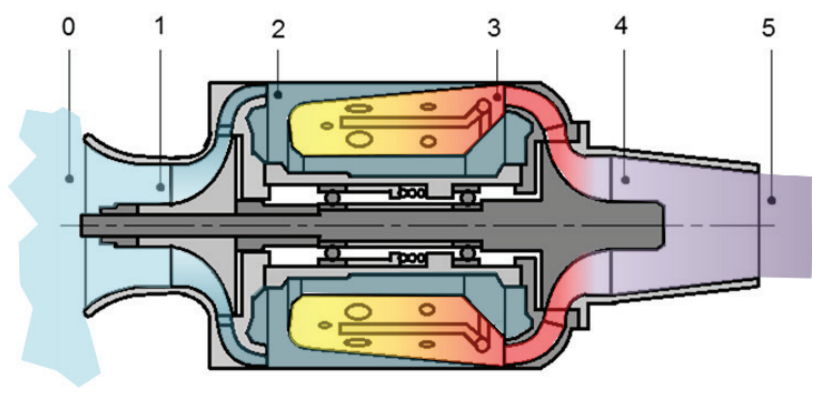

Figure 1. Major aerodynamic stations of the micro turbojet engine

\subsection{Linearized state space representation}

Although turbojet engines can be described by non-linear thermodynamic laws, one can investigate their operation in the neighborhood of a specified working point using linear models. The model can be deduced in a similar way as it was proposed by Beneda, Andoga, and Föző (2018). Using a linear representation instead of a non-linear one greatly simplifies the control system; however, changes in the plant structure require either robust control laws to mitigate the effect of non-linearity like $\mathrm{H}_{\infty}$ or linear quadratic approaches, or the control can be adapted to different operating modes with gain scheduling or linear, parameter varying control systems. In the present research, the LQI method has been selected, as described later in details.

Linear quadratic methods require state space representation. The non-linear functions, which describe the operation of the turbojet engine, can be replaced by their multivariable Taylor series; the resulting matrix equations are the following according to Williams and Lawrence (2007). Equation (1) shows the formula after transformation, which neglects the higher order terms of the Taylor series as

$$
\left.\begin{array}{c}
\stackrel{\ddot{y}}{\tilde{x}}(t)=\mathbf{A} \tilde{x}(t)+\mathbf{B} \tilde{u}(t) \\
\tilde{y}(t)=\mathbf{C} \tilde{x}(t)
\end{array}\right\} .
$$

The turbojet engine shows three main storage possibilities; these are the kinetic energy of the rotor, heat energy and mass of gas in the combustion chamber. These properties can be expressed as changes in $n, p_{3}{ }^{*}$ and $T_{3}{ }^{*}$. The corresponding state vector is defined in equation (2).

$$
x=\left[\begin{array}{lll}
n & p_{3}^{*} & T_{3}^{*}
\end{array}\right]^{T} .
$$

The present engine includes a single input, which is the fuel injection. Therefore, the input vector is practically a scalar, as represented in (3).

$$
u=\dot{m}_{f u e l} \text {. }
$$

The linearization technique is widely used approach in the design of turbine engine control systems. The novelty of the present solution in contrast to conventional turbojet control systems where the output is either rotor speed or engine pressure ratio, here TPR is used which is defined in the following equation (4). In the original form, it was based on compressor pressure ratio including $p_{2}{ }^{*}$. Now it is converted to an expression of $p_{3}{ }^{*}$ using $\sigma_{C C}$ because the latter is a state variable of the present system. This parameter is used by Rolls-Royce commercial turbofan power plants and has an accurate indication of thrust declared by Davies, Holt, and Griffin (2006). However, as it does not comprise variables that are not available in turbojets, furthermore the relationship between thrust and TPR is almost perfectly linear as it has been proved by Beneda (2015), these engines can also benefit from this.

$$
y=T P R=\frac{p_{2}^{*}}{p_{1}^{*}} \sqrt{\frac{T_{3}^{*}}{T_{1}^{*}}}=\frac{p_{3}^{*}}{p_{1}^{*} \sigma_{C C}} \sqrt{\frac{T_{3}^{*}}{T_{1}^{*}}} .
$$

In a physical viewpoint, $p_{3}{ }^{*}$ is a dynamic variable directly due to the cooperation between compressor and turbine, $p_{2}{ }^{*}$ is just following according to the compressor characteristic map. The usage of $p_{3}{ }^{*}$ is suggested by several other sources as well, it can be understood as an often used solution, and a physical explanation can be found in Elkhateeb, Badr, and Abouelsoud (2014).

Note that the usage of turbine inlet pressure $p_{3}{ }^{*}$ requires the introduction of combustion chamber pressure recovery factor in the denominator as well. This is neither simple substitution nor neglect therefore. The advantage of this change allows one to use system state parameter $p_{3}{ }^{*}$, which is assumed to be an average pressure inside the entire combustion liner. This pressure $p_{3}{ }^{*}$ in turn is proportional to the gas mass temporarily contained within combustion chamber, that strongly affects the operation of the gas turbine. This assumption has been utilized by Elkhateeb et al. (2014).

The dynamic behavior depends on the storage of kinetic energy in the rotating assembly, heat energy and mass storage in the combustion chamber. The first can be described by the unbalance of turbine and compressor powers that results in a net acceleration as represented in (5).

$$
\dot{n}=\frac{P_{T} \eta_{m}-P_{C}}{\grave{\mathrm{E}}(\pi / 30)^{2} n} .
$$

In steady state conditions the sum of compressor air and fuel mass flow rates are entering into the turbine. In a transient, dynamic situation there can be an imbalance between incoming and outgoing mass flow rates, resulting in either concentration or depletion of mass inside the combustion chamber. This effect can be organized into an expression of the variation of total pressure due to the ideal gas law as shown in (6). 


$$
\dot{p}_{3}^{*}=\frac{p_{3}^{*}}{T_{3}^{*}} \dot{T}_{3}^{*}+\frac{R_{g} T_{3}^{*}}{V_{C C}}\left(\dot{m}_{2}+\dot{m}_{f u e l}-\dot{m}_{3}\right) .
$$

When one examines the heat storage capability of the combustion chamber, it is the internal energy of the gas which temporarily resides inside this cavity. According to ideal gas assumption, the internal energy can be written as the product of isochoric specific heat and total temperature. Furthermore, this expression can be arranged to show the variation of turbine inlet total temperature as indicated in (7).

$$
\begin{aligned}
& \dot{T}_{3}^{*}=\frac{1}{c_{v} m_{C C}}\left[\left(\dot{m}_{2} i_{2}^{*}+\dot{m}_{f u e l} H_{a} \eta_{C C}-\dot{m}_{3} i_{3}^{*}\right)-\right. \\
& \left.c_{v} \mathrm{~T}_{3}^{*}\left(\dot{m}_{2}+\dot{m}_{\text {fuel }}-\dot{m}_{3}\right)\right]
\end{aligned}
$$

The system matrix $\mathbf{A}$, which contains the mutual response of the system states based on each other's variation, can be described as the first partial derivatives, as indicated in (8). In the following section, the particular derivatives are represented.

$$
\mathbf{A}=\left[\begin{array}{lll}
\frac{\partial \dot{n}}{\partial n} & \frac{\partial \dot{n}}{\partial p_{3}^{*}} & \frac{\partial \dot{n}}{\partial T_{3}^{*}} \\
\frac{\partial \dot{p}_{3}^{*}}{\partial n} & \frac{\partial \dot{p}_{3}^{*}}{\partial p_{3}^{*}} & \frac{\partial \dot{p}_{3}^{*}}{\partial T_{3}^{*}} \\
\frac{\partial \dot{T}_{3}^{*}}{\partial n} & \frac{\partial \dot{T}_{3}^{*}}{\partial p_{3}^{*}} & \frac{\partial \dot{T}_{3}^{*}}{\partial T_{3}^{*}}
\end{array}\right] .
$$

\subsection{Partial derivatives of rotor speed dynamic equation}

The partial derivative of the rotor speed equation can be written after expressing turbine and compressor powers as a function of their respective mass flow rates, work and efficiency. The efficiency of the turbine can be regarded as a constant value therefore its change is neglected in the rest of the article. Mass flow rates can be transformed into non-dimensional gas dynamic functions, which depend on corrected speed and pressure ratio of compressor and turbine, respectively. The resulting equation is briefly presented in (9), with its members detailed further in the subsequent formulae.

$$
\begin{aligned}
& \frac{\partial \dot{n}}{\partial n}=\frac{1}{\Theta(\pi / 30)^{2} n}\left[\frac{P_{T} \eta_{m}}{q\left(\lambda_{3}\right)} \frac{\partial q\left(\lambda_{3}\right)}{\partial n}-\right. \\
& \left.\frac{P_{C}}{q\left(\lambda_{1}\right)} \frac{\partial q\left(\lambda_{1}\right)}{\partial n}+\frac{P_{C}}{\eta_{C}} \frac{\partial \eta_{C}}{\partial n}\right]+\frac{\dot{n}}{n}
\end{aligned}
$$

According to the compressor and turbine characteristic maps, dimensionless mass flow rates of the two units and compressor isentropic efficiency depend on engine rotating speed. These variables can be best expressed as nonlinear functions over a wide range of operating conditions. Due to the restriction of the fixed area exhaust nozzle the engine has a cooperation along a single curve in the compressor map. This condition allows to simplify the correla- tions into bilinear approximations as the engine does not deviate significantly from this curve during its operation. The bilinear equation for compressor dimensionless mass flow rate is indicated in (10) as a function of corrected rotor speed and compressor pressure ratio expressed with turbine inlet total pressure, which is a state of the plant. The coefficients $a_{1}-a_{4}$ must be subsequently determined using compressor characteristic map.

$$
q\left(\lambda_{1}\right)=\frac{a_{1} n}{\sqrt{T_{1}^{*}}} \frac{p_{3}^{*}}{\sigma_{C C} p_{1}^{*}}+\frac{a_{2} n}{\sqrt{T_{1}^{*}}}+\frac{a_{3} p_{3}^{*}}{\sigma_{C C} p_{1}^{*}}+a_{4} .
$$

Equation (11) describes the change of compressor isentropic efficiency as a function of corrected rotor speed and dimensionless mass flow rate. As centrifugal compressors have typically wider range of stable mass flow rates, it is logical to create a function of mass flow rate instead of pressure ratio. The determination of coefficients $b_{1}-b_{4}$ is described later.

$$
\eta_{C}=b_{1} \frac{n}{\sqrt{T_{1}^{*}}} q\left(\lambda_{1}\right)+b_{2} q\left(\lambda_{1}\right)+b_{3} \frac{n}{\sqrt{T_{1}^{*}}}+b_{4} .
$$

For the dimensionless mass flow rate in the turbine, a different corrected speed definition is used, which takes turbine inlet total temperature and turbine throat area into consideration, indicated by $K_{T}$. Equation (12) also includes the dependence on turbine inlet and exhaust outlet total pressures, the former being a state variable, the latter considered as constant for a narrow neighborhood of a selected operating point. As the coefficients of compressor mass flow rate and efficiency, the values for factors $c_{1}-c_{4}$ are described later in this article.

$$
q\left(\lambda_{3}\right)=\frac{c_{1} K_{T} n}{\sqrt{T_{3}^{*}}} \frac{\sigma_{D} p_{3}^{*}}{p_{5}^{*}}+\frac{c_{2} K_{T} n}{\sqrt{T_{3}^{*}}}+\frac{c_{3} \sigma_{D} p_{3}^{*}}{p_{5}^{*}}+c_{4} .
$$

After these functions have been defined, the partial derivatives can be expressed to complete (9) as listed in equations (13)-(15).

$$
\begin{aligned}
& \frac{\partial q\left(\lambda_{1}\right)}{\partial n}=\frac{a_{1}}{\sqrt{T_{1}^{*}}} \frac{p_{3}^{*}}{\sigma_{C C} p_{1}^{*}}+\frac{a_{2}}{\sqrt{T_{1}^{*}}} \\
& \frac{\partial \eta_{C}}{\partial n}=\frac{\partial q\left(\lambda_{1}\right)}{\partial n}\left(\frac{b_{1} n}{\sqrt{T_{1}^{*}}}+b_{2}\right)+\frac{b_{1} q\left(\lambda_{1}\right)}{\sqrt{T_{1}^{*}}}+\frac{b_{3}}{\sqrt{T_{1}^{*}}} ; \\
& \frac{\partial q\left(\lambda_{3}\right)}{\partial n}=\frac{K_{T}}{\sqrt{T_{3}^{*}}}\left(\frac{c_{1} \sigma_{D} p_{3}^{*}}{p_{5}^{*}}+c_{2}\right) .
\end{aligned}
$$

The next step is to determine the dependency of rotor speed derivative on turbine inlet total pressure. This state variable is found hidden in the turbine and compressor powers, as both of them depend on this parameter. This can be evaluated in (16).

$$
\frac{\partial \dot{n}}{\partial p_{3}^{*}}=\frac{1}{\grave{\mathrm{E}}(\pi / 30)^{2} n}\left(\eta_{m} \frac{\partial P_{T}}{\partial p_{3}^{*}}-\frac{\partial P_{C}}{\partial p_{3}^{*}}\right) .
$$

The dependency is threefold in the case of turbine power, as the turbine mass flow rate itself contains a to- 
tal pressure factor and the dimensionless mass flow rate was described by (12). The third aspect is the part of the specific work that depends on the pressure ratio, hence the pressure itself as well. The turbine power derivative is indicated in (17).

$$
\frac{\partial P_{T}}{\partial p_{3}^{*}}=\frac{P_{T}}{p_{3}^{*}}+\frac{P_{T}}{q\left(\lambda_{3}\right)} \frac{\partial q\left(\lambda_{3}\right)}{\partial p_{3}^{*}}-\frac{P_{T}\left(\pi_{T}\right)^{\frac{1}{\kappa_{g}}}}{1-\left(\pi_{T}\right)^{\frac{1-\kappa_{g}}{\kappa_{g}}}} \frac{\left(\kappa_{g}-1\right) p_{5}^{*}}{\kappa_{g}\left(p_{3}^{*}\right)^{2} \sigma_{D}} .
$$

The compressor power has similarly threefold dependence, but instead of mass flow rate, here the efficiency represents the third member of the equation, from which the corresponding partial derivative is described in (18).

$$
\frac{\partial P_{C}}{\partial p_{3}^{*}}=-\frac{P_{C}}{q\left(\lambda_{1}\right)} \frac{\partial q\left(\lambda_{1}\right)}{\partial p_{3}^{*}}+\frac{P_{C}}{\eta_{C}} \frac{\partial \eta_{C}}{\partial p_{3}^{*}}-\frac{P_{C}\left(\pi_{C}\right)^{-\frac{1}{\kappa_{a}}}}{\left(\pi_{C}\right)^{\frac{\kappa_{a}-1}{\kappa_{a}}}-1} \frac{\left(\kappa_{a}-1\right)}{\kappa_{a} p_{1}^{*} \sigma_{C C}} \text {. }
$$

The inner derivatives of (17) and (18) can be expressed similarly to complete (16), these are shown in (19)-(21).

$$
\begin{aligned}
& \frac{\partial q\left(\lambda_{1}\right)}{\partial p_{3}^{*}}=\frac{1}{\sigma_{C C} p_{1}^{*}}\left(\frac{a_{1} n}{\sqrt{T_{1}^{*}}}+a_{3}\right) ; \\
& \frac{\partial \eta_{C}}{\partial p_{3}^{*}}=\frac{\partial q\left(\lambda_{1}\right)}{\partial p_{3}^{*}}\left(\frac{b_{1} n}{\sqrt{T_{1}^{*}}}+b_{2}\right) ; \\
& \frac{\partial q\left(\lambda_{3}\right)}{\partial p_{3}^{*}}=\frac{\sigma_{D}}{p_{5}^{*}}\left(\frac{c_{1} K_{T} n}{\sqrt{T_{3}^{*}}}+c_{3}\right) .
\end{aligned}
$$

The derivative of turbine inlet total temperature contains two members; one obtained directly from the mass flow rate and the other resulting from the $q\left(\lambda_{3}\right)$ dependency on $T_{3}{ }^{*}$. The overall expression is defined in (22) and the dimensionless mass flow rate subderivative can be found in (23):

$$
\begin{aligned}
& \frac{\partial \dot{n}}{\partial T_{3}^{*}}=\frac{P_{T} \eta_{m}}{\grave{\mathrm{E}}(\pi / 30)^{2} n}\left[\frac{1}{2 T_{3}^{*}}+\frac{1}{q\left(\lambda_{3}\right)} \frac{\partial q\left(\lambda_{3}\right)}{\partial T_{3}^{*}}\right] ; \\
& \frac{\partial q\left(\lambda_{3}\right)}{\partial T_{3}^{*}}=\frac{K_{T} n}{2 T_{3}^{*} \sqrt{T_{3}^{*}}}\left(\frac{c_{1} \sigma_{D} p_{3}^{*}}{p_{5}^{*}}+c_{2}\right) .
\end{aligned}
$$

\subsection{Partial derivatives of turbine inlet total pressure dynamic equation}

The partial derivative of rotor speed can be written as shown in (24) due to the air and gas mass flow rates dependency on rotor speed. There are members of the equation which already have been defined in (13) and (15), respectively.

$$
\frac{\partial \dot{p}_{3}^{*}}{\partial n}=\frac{R_{g} T_{3}^{*}}{V_{C C}}\left[\frac{\dot{m}_{2}}{q\left(\lambda_{1}\right)} \frac{\partial q\left(\lambda_{1}\right)}{\partial n}-\frac{\dot{m}_{3}}{q\left(\lambda_{3}\right)} \frac{\partial q\left(\lambda_{3}\right)}{\partial n}\right] .
$$

The dependency on turbine inlet total pressure $p_{3}{ }^{*}$ is shown by the corresponding derivative as indicated in (25). The compressor mass flow rate depends on this parameter due to compressor characteristics, turbine mass flow rate has an additional aspect of gas dynamics, this is described by the center term in the brackets.

$$
\frac{\partial \dot{p}_{3}^{*}}{\partial p_{3}^{*}}=\frac{\dot{T}_{3}^{*}}{T_{3}^{*}}+\frac{R_{g} T_{3}^{*}}{V_{C C}}\left[\frac{\dot{m}_{2}}{q\left(\lambda_{1}\right)} \frac{\partial q\left(\lambda_{1}\right)}{\partial p_{3}^{*}}-\frac{\dot{m}_{3}}{p_{3}^{*}}-\frac{\dot{m}_{3}}{q\left(\lambda_{3}\right)} \frac{\partial q\left(\lambda_{3}\right)}{\partial p_{3}^{*}}\right] \text {. }
$$

The derivative of turbine inlet total temperature is shown in (26). It consists of three parts; the first term is the change of the temperature, the second describes turbine inlet mass flow rate change, the third term stands for the change of mass in the combustion chamber.

$$
\begin{aligned}
& \frac{\partial \dot{p}_{3}^{*}}{\partial T_{3}^{*}}=-p_{3}^{*} \frac{\dot{T}_{3}^{*}}{\left(T_{3}^{*}\right)^{2}}+\frac{p_{3}^{*}}{m_{C C}} \frac{\dot{m}_{3}}{q\left(\lambda_{3}\right)} \frac{\partial q\left(\lambda_{3}\right)}{\partial T_{3}^{*}}- \\
& \frac{R_{g}}{V_{C C}}\left[\dot{m}_{2}+\dot{m}_{f u e l}-\dot{m}_{3}\right]
\end{aligned} .
$$

\subsection{Partial derivatives of turbine inlet total temperature dynamic equation}

The dependency of $T_{3}^{*}$ on rotor speed $n$ lies implicitly in mass flow rates. As fuel injection is the input and does not depend on state variables, the middle term will be eliminated from the expression of the partial derivative, which is shown in (27).

$$
\begin{aligned}
& \frac{\partial \dot{T}_{3}^{*}}{\partial n}=\frac{1}{c_{v} m_{C C}}\left[c_{v} T_{3}^{*}\left(\frac{\dot{m}_{3}}{q\left(\lambda_{3}\right)} \frac{\partial q\left(\lambda_{3}\right)}{\partial n}-\frac{\dot{m}_{2}}{q\left(\lambda_{1}\right)} \frac{\partial q\left(\lambda_{1}\right)}{\partial n}\right)-\right. \\
& \left.\frac{\dot{m}_{3} c_{p g} T_{3}^{*}}{q\left(\lambda_{3}\right)} \frac{\partial q\left(\lambda_{3}\right)}{\partial n}+\dot{m}_{2} c_{p a}\left(\frac{T_{2}^{*}}{q\left(\lambda_{1}\right)} \frac{\partial q\left(\lambda_{1}\right)}{\partial n}-\frac{T_{2}^{*}}{\eta_{C}} \frac{\partial \eta_{C}}{\partial n}\right)\right]
\end{aligned}
$$

The turbine inlet total temperature change is affected by $p_{3}{ }^{*}$ through mass flow rates mostly, as represented in (28).

$$
\begin{aligned}
& \frac{\partial \dot{T}_{3}^{*}}{\partial p_{3}^{*}}=\frac{\dot{m}_{2} c_{p a} T_{2}^{*}}{c_{v} m_{C C}}\left[\frac{1}{q\left(\lambda_{1}\right)} \frac{\partial q\left(\lambda_{1}\right)}{\partial p_{3}^{*}}+\frac{\kappa_{a}-1}{\kappa_{a}} \frac{1}{p_{3}^{*}}\right]- \\
& \frac{\dot{m}_{3} c_{p g} T_{3}^{*}}{q\left(\lambda_{3}\right)}\left[\frac{1}{p_{3}^{*}}-\frac{1}{q\left(\lambda_{3}\right)} \frac{\partial q\left(\lambda_{3}\right)}{\partial p_{3}^{*}}\right]- \\
& \frac{T_{3}^{*}}{m_{C C}}\left[\frac{\dot{m}_{3}}{p_{3}^{*}}-\frac{\dot{m}_{3}}{q\left(\lambda_{3}\right)} \frac{\partial q\left(\lambda_{3}\right)}{\partial p_{3}^{*}}+\frac{\dot{m}_{2}}{q\left(\lambda_{1}\right)} \frac{\partial q\left(\lambda_{1}\right)}{\partial p_{3}^{*}}\right] .
\end{aligned}
$$

One can find the corresponding dependency of the dynamic equation for turbine inlet total temperature on this particular variable as well. This can be written as stated in (29), containing terms of turbine entry total enthalpy, internal energy in the combustion chamber and their respective internal members regarding turbine inlet dimensionless mass flow rate. 


$$
\begin{aligned}
& \frac{\partial \dot{T}_{3}^{*}}{\partial T_{3}^{*}}=\frac{1}{c_{v} m_{C C}}\left[\frac{\dot{m}_{3} c_{p g} T_{3}^{*}}{q\left(\lambda_{3}\right)} \frac{\partial q\left(\lambda_{3}\right)}{\partial T_{3}^{*}}-\dot{m}_{3} c_{p g}-\right. \\
& \left.c_{v}\left(\dot{m}_{2}+\dot{m}_{f u e l}-\dot{m}_{3}\right)-c_{v} T_{3}^{*}\left(\frac{\dot{m}_{3}}{2 T_{3}^{*}}+\frac{\dot{m}_{3} c_{p g} T_{3}^{*}}{q\left(\lambda_{3}\right)} \frac{\partial q\left(\lambda_{3}\right)}{\partial T_{3}^{*}}\right)\right]
\end{aligned}
$$

\subsection{Dependencies on system input}

As it has been defined in (3), the system input is the single scalar fuel mass flow rate. Evaluating (5), one can state that this variable is not included in the expression for rotor speed in any direct or indirect form, so the first member of input matrix (that is a 3-by-1 column vector) is zero.

In (6) and (7) there are direct substitutions of fuel mass flow rate into both respective expressions. The former contains only a single member depending on fuel mass flow rate; hence its final form is simpler than the other's. Equations (30) and (31) represent the partial derivatives of turbine inlet total pressure and temperature. The former one can be further rewritten as the ratio of turbine inlet total pressure and gas mass contained within the combustion chamber, after taking the ideal gas law into consideration.

$$
\begin{aligned}
& \frac{\partial \dot{p}_{3}^{*}}{\partial \dot{m}_{f u e l}}=\frac{R_{g} T_{3}^{*}}{V_{C C}}=\frac{p_{3}^{*}}{m_{C C}} ; \\
& \frac{\partial \dot{T}_{3}^{*}}{\partial \dot{m}_{f u e l}}=\frac{H_{a} \eta_{C C}-c_{v} T_{3}^{*}}{c_{v} m_{C C}}=\frac{H_{a} \eta_{C C}}{c_{v} m_{C C}}-\frac{T_{3}^{*}}{m_{C C}} .
\end{aligned}
$$

Thus, the input matrix is composed of the previously deducted quantities as (32) shows it in a transposed form.

$$
\mathbf{B}=\left[\frac{\partial \dot{n}}{\partial \dot{m}_{f u e l}}=0 \frac{p_{3}^{*}}{m_{C C}} \frac{H_{a} \eta_{C C}}{c_{v} m_{C C}}-\frac{T_{3}^{*}}{m_{C C}}\right] .
$$

\subsection{Special features of the model due to TPR control}

The output chosen for the present investigation is TPR as stated in the introduction which is defined according to (4). This parameter changes in a nonlinear manner throughout the entire operating range, reflecting the basic behavior of the power plant. In contrast to rotor speed control, where the state variable can be immediately used as an output, here two states appear in the expression of $\mathrm{TPR}$, the turbine inlet total temperature having a square root term as well. Regarding these considerations, the output vector of the present system can be described in (33).

$$
\mathbf{C}=\left[\begin{array}{lll}
\frac{\partial T P R}{\partial n}=0 & \frac{\partial T P R}{\partial p_{3}^{*}} & \frac{\partial T P R}{\partial T_{3}^{*}}
\end{array}\right] .
$$

The derivative of turbine inlet stagnation pressure is simple, as (4) comprises a single linear factor of $p_{3}{ }^{*}$, as shown in (34).

$$
\frac{\partial T P R}{\partial p_{3}^{*}}=\frac{1}{p_{1}^{*} \sigma_{C C}} \sqrt{\frac{T_{3}^{*}}{T_{1}^{*}}} .
$$

The derivative of turbine inlet total temperature is slightly more complex due to the square root of this parameter as described by (35).

$$
\frac{\partial T P R}{\partial T_{3}^{*}}=\frac{p_{3}^{*}}{2 T_{1}^{*} p_{1}^{*} \sigma_{C C}} \sqrt{\frac{T_{1}^{*}}{T_{3}^{*}}} .
$$

It is also important to highlight the benefits of the TPR control against traditional systems using rotor speed or Engine Pressure Ratio as control parameter. Therefore, the model had to be expanded and it also contains the following calculation, which is a supplementary routine besides the main computations performed by the model, that determines the EPR and thrust of the engine. The EPR can be obtained from compressor-turbine cooperation, which is not necessarily an equilibrium. Hence the following steps are necessary.

Firstly, compressor dimensionless mass flow rate $q\left(\lambda_{1}\right)$ and efficiency $\eta_{C}$, and turbine dimensionless mass flow rate $q\left(\lambda_{3}\right)$ are determined using equations (10) through (12). Then the mass flow rates can be quantified based on the following definition of dimensionless mass flow rate, where the appropriate indices must be substituted to acquire compressor or turbine related values.

$$
\dot{m}=\frac{\beta A q(\lambda) p^{*}}{\sqrt{T^{*}}} .
$$

In (36) the symbol $\beta$ is a gas dynamic constant that can be calculated as shown in (37), which is a function of critical temperature ratio $\left(\frac{2}{\kappa+1}\right)$.

$$
\beta=\sqrt{\frac{\kappa}{R}\left(\frac{2}{\kappa+1}\right)^{\frac{\kappa+1}{\kappa-1}}} .
$$

As a next step, compressor power can be computed as a multiplication of compressor mass flow rate, specific heat of air at constant pressure and total temperature difference across the compressor, which is declared in (38). It also contains an explanation how total temperature at compressor discharge can be determined using pressure ratio of the compressor and its efficiency.

$$
P_{C}=\dot{m}_{1} c_{p a} T_{1}^{*} \frac{\left(\pi_{C}^{\frac{\kappa-1}{\kappa}}-1\right)}{\eta_{C}} .
$$

Due to the dynamic Turbine power cannot be calculated according to the same structure indicated in (38), because during transients compressor and turbine powers are not balanced, therefore one cannot determine $T_{4}^{*}$ turbine outlet total temperature from equilibrium conditions. However, if one reorganizes (5), the turbine power can be computed as shown in (40). 


$$
P_{T}=\frac{\dot{n} n \Theta(\pi / 30)^{2}+P_{C}}{\eta_{m}} .
$$

As a consequence, rearranging turbine power yields turbine outlet total temperature according to (41).

$$
T_{4}^{*}=T_{3}^{*}-\frac{P_{T}}{\dot{m}_{3} c_{p g}} .
$$

Turbine outlet total pressure can be calculated using temperatures and efficiency, the latter estimated by constant value according to the manufacturer's characteristic map. As EPR is defined as the ratio of nozzle inlet total pressure $p_{5}{ }^{*}$ and compressor inlet total pressure $p_{1}{ }^{*}$, one can determine the $p_{5}{ }^{*}$ from $p_{4}{ }^{*}$ with a multiplication by a pressure recovery factor $\sigma_{D}$ at the nozzle describing its losses. This can be evaluated in (42).

$$
E P R=\frac{p_{5}^{*}}{p_{1}^{*}}=\frac{\sigma_{D} p_{4}^{*}}{p_{1}^{*}}=\frac{\sigma_{D}}{p_{1}^{*}} p_{3}^{*}\left[1-\frac{T_{3}^{*}-T_{4}^{*}}{T_{3}^{*} \eta_{T}}\right]^{\frac{\kappa_{g}}{\kappa_{g}-1}} .
$$

As EPR strongly contributes to the exhaust velocity, the thrust of the engine can be calculated by the formula shown in (43). In this equation, we neglect several parts of the complete formula of thrust force, because the engine test bench is static and the nozzle pressure ratio does not reach critical values, therefore exhaust static pressure equals to ambient static pressure. One can also exploit the fact that total temperature does not change in the nozzle downstream of turbine outlet so turbine outlet total temperature $T_{4}^{*}$ can be substituted into this formula.

$$
F_{T}=\dot{m}_{3} \sqrt{\left.\frac{2 \kappa_{g}}{\kappa_{g}-1} R_{g} T_{4}^{*}\left(1-\frac{1}{E P R}\right) \eta_{N}^{\frac{\kappa_{g}-1}{\kappa_{g}}}\right)} .
$$

\section{Identification of the micro turbojet engine}

\subsection{Main constants of the linear model}

The mathematical model presented in the previous section should be filled with real parameters describing the behavior of the gas turbine engine. For this reason, one can divide the values into two main groups. One group of physical constants and geometry or process related values that can be considered unchanged during engine operation; and those, which require a measurement. The former parameters are listed in Table 1; the latter ones are detailed in the next subsection.

\subsection{Measurement of the nominal operating point}

The authors have conducted a measurement on a real turbojet engine to acquire the necessary information for completing the model at a selected nominal operating point. The engine was run at different throttle settings to supply data for various operating points, this will be important later, when a linear parameter varying model will be constructed. This article focuses on a single operating point, which is the nominal, the highest power setting according to the yellow highlighted range in Figure 2. Another set of data is indicated with green background in Figure 2, this transient condition will later be used to validate the identified model.

The primary parameters that have been measured were averaged over the highlighted period, these values are indicated in Table 2 with normal typeset numbers. There are some variables, which are derived using thermodynamic laws, these are highlighted by italic numbers. The boldface numbers represent values determined from cooperation and compressor or turbine characteristic maps.

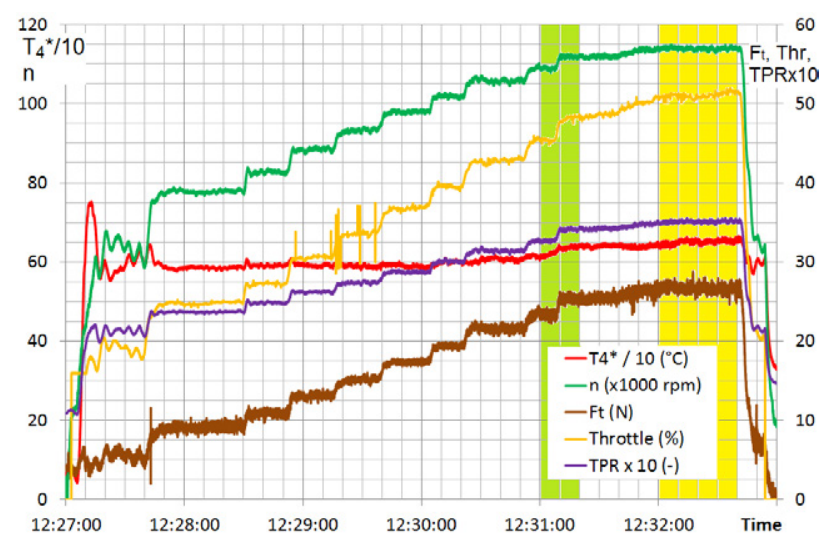

Figure 2. Measurement of gas turbine operation - yellow highlight: selected nominal operating point, green highlight: selected transient to validate model

Table 1. Geometry of gas turbine and physical properties of gas

\begin{tabular}{|c|c|c|}
\hline Symbol & Value & Unit \\
\hline$\Theta$ & $3.11 \cdot 10^{-5}$ & $\mathrm{~kg} \cdot \mathrm{m}^{2}$ \\
\hline$K_{T}$ & $7.62 \cdot 10^{-3}$ & $\mathrm{~m} \sqrt{\mathrm{Jkg}^{-1} \mathrm{~K}^{-1}}$ \\
\hline$V_{C C}$ & $4.20 \cdot 10^{-4}$ & $\mathrm{~m}^{3}$ \\
\hline$\beta_{\mathrm{g}}$ & 0.0396 & $\sqrt{\mathrm{kgKJ}^{-1}}$ \\
\hline$\beta_{\mathrm{a}}$ & 0.0404 & $\sqrt{\mathrm{kgKJ}^{-1}}$ \\
\hline
\end{tabular}

\begin{tabular}{|c|c|c|}
\hline Symbol & Value & Unit \\
\hline$A_{1}$ & $1.116 \cdot 10^{-3}$ & $\mathrm{~m}^{2}$ \\
\hline$A_{3}$ & $3.879 \cdot 10^{-4}$ & $\mathrm{~m}^{2}$ \\
\hline$\kappa_{\mathrm{g}}$ & 1.333 & - \\
\hline$\kappa_{\mathrm{a}}$ & 1.4 & - \\
\hline$\eta_{\mathrm{m}}$ & 0.99 & - \\
\hline
\end{tabular}

\begin{tabular}{|c|c|c|}
\hline Symbol & Value & Unit \\
\hline$H_{a}$ & 42000 & $\mathrm{kJkg}^{-1}$ \\
\hline$R_{g}$ & 288 & $\mathrm{Jkg}^{-1} \mathrm{~K}^{-1}$ \\
\hline$c_{p g}$ & 1152.9 & $\mathrm{Jkg}^{-1} \mathrm{~K}^{-1}$ \\
\hline$c_{p a}$ & 1005.9 & $\mathrm{Jkg}^{-1} \mathrm{~K}^{-1}$ \\
\hline$c_{v}$ & 864.9 & $\mathrm{Jkg}^{-1} \mathrm{~K}^{-1}$ \\
\hline
\end{tabular}

\begin{tabular}{|c|c|c|}
\hline Symbol & Value & Unit \\
\hline$\eta_{\mathrm{T}}$ & 0.86 & - \\
\hline$\eta_{\mathrm{CC}}$ & 0.95 & - \\
\hline$\delta$ & 0.01 & - \\
\hline$\sigma_{C C}$ & 0.95 & - \\
\hline$\sigma_{D}$ & 0.99 & - \\
\hline
\end{tabular}


Table 2. Measured and computed values of gas turbine process parameters

\begin{tabular}{|c|c|c|}
\hline Symbol & Value & Unit \\
\hline$n$ & 113900 & $r p m$ \\
\hline$q\left(\lambda_{1}\right)$ & $\mathbf{0 . 2 8 9}$ & - \\
\hline$q\left(\lambda_{3}\right)$ & 0.904 & - \\
\hline$P_{C}$ & 6441.5 & $W$ \\
\hline$P_{T}$ & 6560.8 & $W$ \\
\hline
\end{tabular}

\begin{tabular}{|c|c|c|}
\hline Symbol & Value & Unit \\
\hline$T_{1}^{*}$ & 283 & $K$ \\
\hline$T_{2}^{*}$ & $\mathbf{3 6 5 . 9}$ & $K$ \\
\hline$T_{3}^{*}$ & 995.6 & $K$ \\
\hline$T_{4}^{*}$ & 923.3 & $K$ \\
\hline$\eta_{C}$ & $\mathbf{0 . 7 2}$ & - \\
\hline
\end{tabular}

\begin{tabular}{|c|c|c|}
\hline Symbol & Value & Unit \\
\hline$p_{1}{ }^{*}$ & 101.85 & $\mathrm{kPa}$ \\
\hline$p_{3}{ }^{*}$ & 194.12 & $\mathrm{kPa}$ \\
\hline$p_{5}{ }^{*}$ & 102.88 & $\mathrm{kPa}$ \\
\hline$\pi_{C}^{*}$ & 1.954 & - \\
\hline$\pi_{T}^{*}$ & 1.906 & - \\
\hline
\end{tabular}

\begin{tabular}{|c|c|c|}
\hline Symbol & Value & Unit \\
\hline$\dot{m}_{2}$ & $\mathbf{0 . 0 7 7 2 6}$ & $\mathrm{kg} \cdot \mathrm{s}^{-1}$ \\
\hline $\bar{b}$ & $\mathbf{0 . 0 7 8 6 9}$ & $\mathrm{kg} \cdot \mathrm{s}^{-1}$ \\
\hline$\dot{m}_{\text {fuel }}$ & 0.001431 & $\mathrm{~kg} \cdot \mathrm{s}^{-1}$ \\
\hline$m_{C C}$ & $2.84 \cdot 10^{-4}$ & $\mathrm{~kg}$ \\
\hline
\end{tabular}

Unfortunately, two parameters, which are state variables, cannot be directly measured, this makes a state observer inevitable later in the development of the control system. For the present investigation, conventional thermodynamic laws were used to obtain non-measureable values, which is more accurate, but slower method, therefore it cannot be used during the real-time control task.

Using the measured outputs of the engine, it was possible to specify the correlation between conventional and novel control parameters and thrust. These values are normalized against their respective maximal values and are plotted versus thrust to show the behavior of different parameters in the entire thrust range, as presented in Figure 3. One can see that the two conventional parameters, Engine Pressure Ratio (EPR) and rotational speed do not have a linear correlation to thrust output. The main advantage of using TPR is that this variable depends linearly on thrust. Assuming endpoint linear approximations, the TPR series exhibit an MSE one magnitude below the same parameter of the others.

The turbojet engine, which is of type PD-60R, was constructed using a turbocharger compressor Garrett T3 '40 trim' and a turbine GT1749. The characteristic map of these units is available from the manufacturer (Garrett turbocharger compressor maps, n.d.; Garrett turbocharger turbine maps, n.d.). Using these available maps and data

from the measurement the nominal operating point can be determined. This is indicated in Figure 4 (based on Garrett turbocharger compressor maps, n.d.).

As it can be seen, the nominal operating point is between 110-121 $10^{3} \mathrm{rpm}$, and the model should be applied to the narrow neighborhood of this point, the previously mentioned bilinear approximation is provided for the compressor. The solid double lines show the real behavior, while the dashed line represent the bilinear approximation results. The wide dashed line connecting the different speed curves represent the operating line of the gas turbine. It can be stated that in the close vicinity of the nominal operating line the bilinear approximation has minimal errors, thus it can be used to estimate compressor behavior. The details are shown in Table 3, together with Mean Square Error that reflects a satisfactory matching of the coefficients. Best approximation resulted for the compressor efficiency, which can be explained by the almost negligible change as indicated on Figure 3.

The turbine characteristic map is used similarly to the previous step. The manufacturer published the turbine map (Garrett turbocharger turbine maps, n.d.) which has been converted to a diagram shown in Figure 5. The change of dimensionless mass flow rate is limited to a minimal deviation in the range of operating pressure ratios, as highlighted in Figure 5.

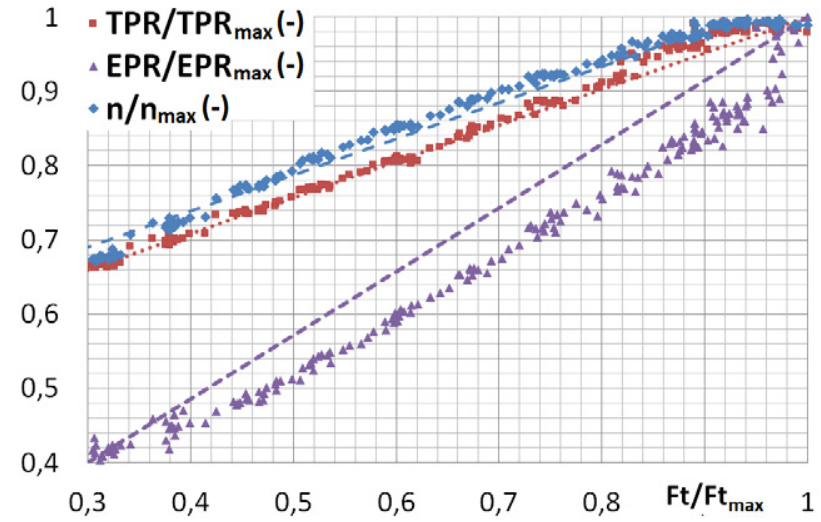

Figure 3. Comparison of different thrust parameters throughout the entire operating range

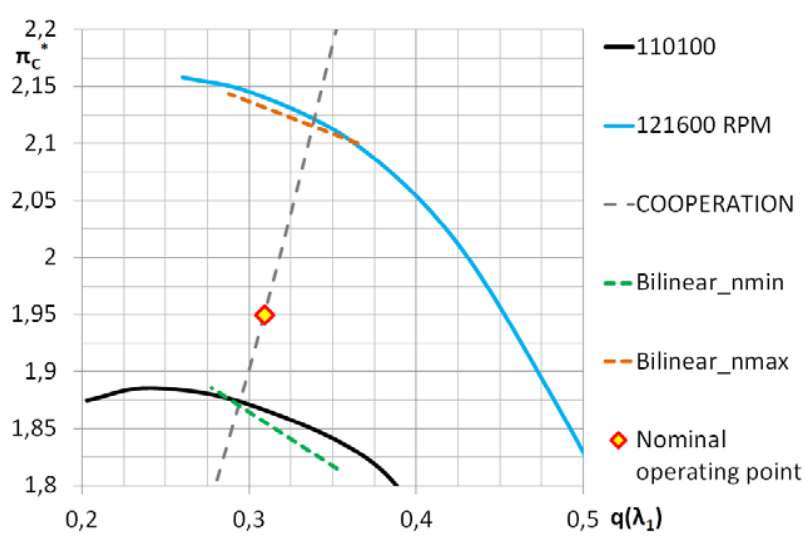

Figure 4. Closeup of compressor characteristic map showing original curves (solid) and bilinear approximations (dashed) in the vicinity of the nominal operating point (based on Garrett turbocharger compressor maps, n.d.) 


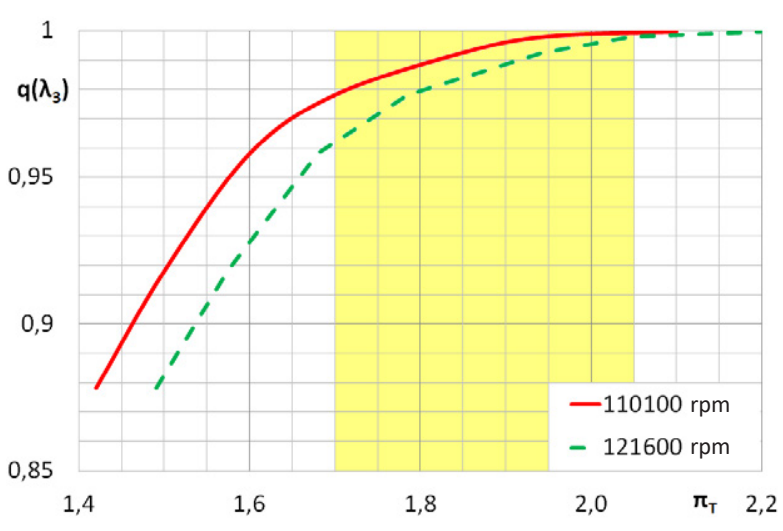

Figure 5. Turbine map (source: Garrett turbocharger turbine maps, n.d.) with operating range highlighted

In order to summarize the resulting model coefficients are represented in the following three equations (44)-(46), which show the values composing the major system matrices.

$$
\begin{aligned}
& \mathbf{A}=\left[\begin{array}{ccc}
-18.15 & 8.066 & 102.5 \\
6500 & -3056 & 52320 \\
-19.25 & 8.371 & -426.5
\end{array}\right] ; \\
& \mathbf{B}=\left[\begin{array}{lll}
0 & 6.749 & 1.552
\end{array}\right] \cdot 10^{8} \\
& \mathbf{C}=\left[\begin{array}{lll}
0 & 1.927 & 188.7
\end{array}\right] \cdot 10^{-5}
\end{aligned}
$$

The system matrices can be subjected to a brief analysis that reveals system behaviour and possibilities for control design. According to standard textbooks about state-space control systems like Williams and Lawrence (2007) one can determine the stability of the plant by determining the eigenvalues of the system matrix A. Using MATLAB@ built-in function eig () all the resulting values are negative, which corresponds an asymptotically stable system, which is true for gas turbine units around their nominal operating point. Another investigation can be made by obtaining controllability $(\mathbf{C o})$ and observability $(\mathbf{O b})$ matrices as presented in equations (47) and (48), respectively. Observability matrix is shown in transposed form for simplicity. If a given matrix has full-row rank, then the system is controllable or observable, respectively.

$$
\begin{aligned}
& \mathbf{C o}=\left[\begin{array}{lllll}
\mathbf{B} & \mathbf{A B} & \mathbf{A}^{2} \mathbf{B} & \ldots & \mathbf{A}^{n-1} \mathbf{B}
\end{array}\right] \\
& \mathbf{O b}=\left[\begin{array}{lllll}
\mathbf{C} & \mathbf{C A} & \mathbf{C A}^{2} & \ldots & \mathbf{C A}^{n-1}
\end{array}\right]^{T} .
\end{aligned}
$$

Calculation can be performed using values from (44) to (46), which shows that both matrices have full rank, i.e. the system is both controllable and observable. First property is inevitable to allow the design of a control system; the second one is essential to develop a state observer for those variables at turbine inlet, which are not measureable in the real environment.

\section{Simulation in MATLAB $^{\circledR}$ Simulink $^{\circledR}$ Environment}

\subsection{Description of simulation software}

The Simulink ${ }^{\circ}$ program has been developed prior to the identification process as MATLAB ${ }^{\circ}$ allows the buildup of a parametric model. The matrix multiplication factors are filled with variable names that reflect members of the actual workspace. After the above detailed identification has taken place, the values determined during this process have been introduced into the workspace. Thus the simulation software has been made ready.

The simulation covers a ten-second time interval, highlighted in Figure 2 with green color, which corresponds a selected segment of the real measurements that should be reproduced by the model. The input is representing the change of fuel supply as it happened during the measurement. As the mathematical model is based on deviations from the selected operating point, all state variables, input and output must be converted back to physical values by adding the nominal values.

For numeric integration the solver ode45 (DormandPrince) scheme is used, with a variable-step size and relative tolerance of $1 \cdot 10^{-3}$. The schematic of the MATLAB ${ }^{\circ}$ Simulink ${ }^{\bullet}$ software is shown in Figure 6. It includes the calculation of state variable derivatives using matrices $\mathbf{A}$ and $\mathbf{B}$, as well as the computation of the output based on matrix $\mathbf{C}$. These matrix multiplications are indicated as green triangles. Yellow blocks are representing standard mathematic operations like addition (circles), vector concatenate (vertical bar) integration and derivation (blocks labeled " $1 / \mathrm{s}$ " and " $\Delta u / \Delta t$ ", respectively). The light blue box in the left top corner contains the initial conditions; the purple rectangles are corresponding to the nominal state variables, input and output, in order to convert the deviations calculated by the model to absolute values. The scopes and the simout allow the offline evaluation of the simulation results.

In order to allow the model to compare different control parameters like rotating speed and EPR to the TPR, the software is equipped with a block labeled "Supplementary calculations". This Matlab function block incorporates those equations which allow determining the thrust (output labeled "Ft") and the EPR. These values are calculated according to the steps mentioned in (36)-(43).

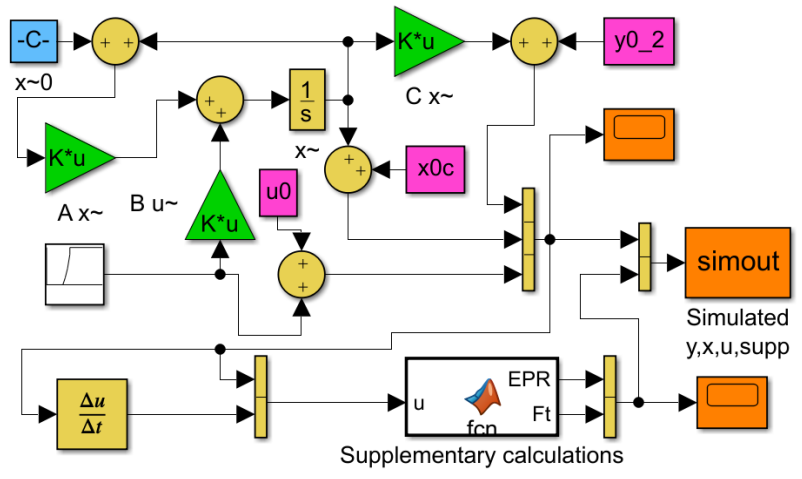

Figure 6. MATLAB ${ }^{\oplus}$ Simulink ${ }^{\oplus}$ software layout 


\subsection{Validating the model}

As it has been stated above the developed mathematical model has been validated with such sequence of measured data which indicate the dynamic behavior of the gas turbine engine in the close vicinity of the nominal operating point. For this reason the green highlighted range of Figure 2 has been selected, and the input of the model $\left(\dot{m}_{f u e l}\right)$ has been set to correspond the measurement. The interpolated data are shown in Table 4. In order to estimate the magnitude of changes, the table also includes the relative change in percentage of the initial fuel flow.

The simulation resulted in a success, as it can be evaluated in Figure 7. The values obtained from measurement either directly or by calculation for each variable are indicated with solid lines. Simulated parameters are represented by dashed lines.

All pairs of quantities reflect a satisfactory matching, particularly rotor speed $n$, turbine inlet total pressure $p_{3}{ }^{*}$ and $F_{T}$ thrust exhibit good correlation with the physical behavior of the plant. Thrust calculation anticipates development of measured thrust, therefore it reaches a peak of $5.81 \%$ maximum relative error during transient, meanwhile the time series have an overall good fit that is represented by the MSE equal to 0.155 .

Red solid line displaying the run of turbine inlet total temperature $T_{3}^{*}$ has a slight delay in contrast to light red dashed simulation results, that can be due to the heat capacity of the sensor resulting in slower response and the

Table 4. Measured fuel flow change used for simulated transient

\begin{tabular}{|c|c|c|c|c|c|c|c|}
\hline Time (s) & 0.00 & 3.00 & 3.33 & 3.66 & 4.00 & 4.33 & 10.0 \\
\hline $\begin{array}{c}\Delta \dot{m}_{\text {fuel }} \\
\left(\cdot 10^{-5} \mathrm{~kg} / \mathrm{s}\right)\end{array}$ & 0.0 & 0.00 & 1.5 & 3.0 & 5.5 & 6.864 & 6.864 \\
\hline$\delta \dot{m}_{\text {fuel }}(\%)$ & 0.0 & 0.00 & 1.10 & 2.19 & 4.02 & 5.01 & 5.01 \\
\hline
\end{tabular}

fact $T_{4}{ }^{*}$ was measured, $T_{3}{ }^{*}$ is just acquired using thermodynamic laws of turbine operation.

The largest steady state error is found in TPR itself, which is shown as percentage of initial value in order to easily fit into the ranges of other parameters.

The numeric evaluation can be carried out according to Table 5. The first line of values indicates the absolute value of relative errors in percentage of nominal (measured) quantities, while the second represents the mean squared error (MSE) terms of each. The highest deviation in both approaches can be found in TPR, the state variables exhibit normalized errors lying around $1 \%$ of the measurement, while MSE of these parameters is approximately $0.1 \ldots 0.2$.

Table 5. Relative and mean squared errors of simulated results

\begin{tabular}{|l|c|c|c|c|c|}
\hline Parameter $(\mathrm{x})$ & $n$ & $p_{3}^{*}$ & $T_{3}^{*}$ & $T P R$ & $F_{T}$ \\
\hline$\left|\delta_{x}\right|_{\max }(\%)$ & 1.115 & 0.972 & 1.093 & 1.455 & 5.812 \\
\hline MSE & 0.097 & 0.291 & 0.218 & 0.485 & 0.155 \\
\hline
\end{tabular}

These results can be evaluated as fully compliant with the measurements, i.e. the mathematical model is able to describe the dynamic behavior of the gas turbine engine in the selected range of operation.

\section{Conclusions}

In the present paper the authors have introduced the state space model of the PD-60R turbojet engine with a turbocharger compressor Garrett T3 '40 trim' and a turbine GT1749, including a non-adjustable exhaust nozzle, which significantly reduced the complexity of the model.

For parameters identification the authors performed measurements on the gas turbine engine with several different steady state operating conditions. The model thermodynamic parameters have been determined using measured data in a single selected steady state operational point, meanwhile geometry and similar mechanical prop-

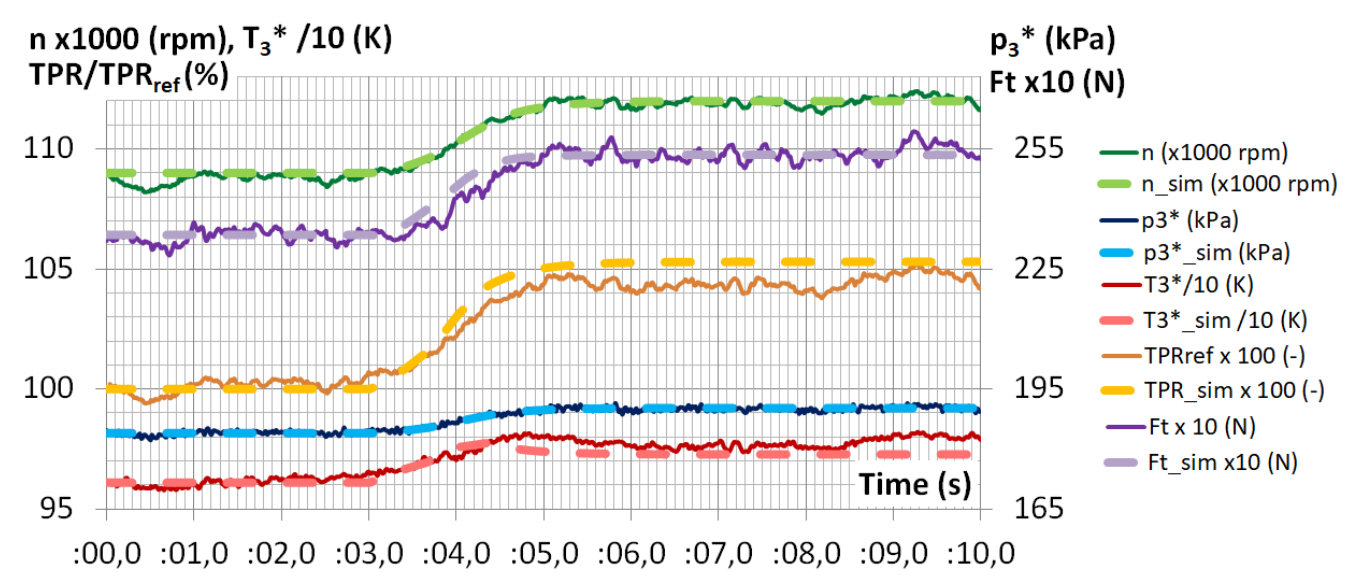

Figure 7. Comparison of values obtained from measurement (solid) and simulation (dashed) 
erties have been measured on the engine during overhaul when it was disassembled completely. For the compressor and turbine operating parameters, the characteristic maps supplied by the manufacturer have been replaced by bilinear correlations, which give enough accuracy for the present model, where there are no significant deviations from the cooperation line due to the fixed exhaust nozzle.

The developed linearized model is valid in the close neighborhood of the selected regime. Therefore, additional measurements to verify the models behavior in different operational situations and further investigations including different regimes must be performed in the future.

Using MATLAB ${ }^{\circledR}$ Simulink $^{\oplus}$, the state space model has been simulated and the results were found satisfactory. The model also includes those additional calculations that make it possible to compare the performance of TPR against conventional solutions like rotational speed or EPR and prove its enhanced capabilities. As the system matrices are represented by workspace variables, the model is flexible and can be easily changed to suit different engine types as well.

The next step of the development should be the establishment of a linear quadratic controller designed for the selected operational point, where the system response can be assumed to remain linear. Due to the need of set point regulation, instead of the Linear Quadratic Controller one has to use the Linear Quadratic Integrating method which ensures not only optimal and robust control, that makes it suitable to work through different operating modes instead of a single point, but provides the possibility of reference tracking.

One must also consider that the selected state variables also comprise non-measurable values, like turbine inlet total temperature, which immediately rises the need for state observer. These considerations must be taken in order to allow a successful design of the control itself based on the present results.

For further research, multiple operating points of the same measurement can be used as a basis for identification throughout the entire operating range, allowing the development of a linear, parameter varying control. Other advanced control laws like sliding mode or model predictive controls are also possible as a future work.

\section{Author contributions}

Károly Beneda has developed the mathematical model, performed the measurement presented in this work and has written the revised form of the article. Khaoula Derbel was responsible for the data analysis, setting up compressor and turbine models, creating and performing simulation and writing the draft of the article.

\section{Disclosure statement}

Authors declare that their article does not have any competing financial, professional, or personal interests from other parties.

\section{References}

Andoga, R., Főző, L., Madarász, L., \& Judičák, J. (2010). Advanced methods of turbojet engines' control. In Proceedings of the IEEE $8^{\text {th }}$ International Symposium on Applied Machine Intelligence and Informatics (SAMI) (pp. 141-144). IEEE Xplore. https://doi.org/10.1109/SAMI.2010.5423749

Beneda, K. (2015). Modular electronic turbojet control system based on TPR. Acta Avionica, 17(1).

Beneda, R. Andoga, R., \& Főző, L. (2018). Linear mathematical model for state-space representation of small scale turbojet engine with variable exhaust nozzle. Periodica Polytechnica Transportation Engineering, 46(1), 1-10. https://doi.org/10.3311/PPtr.10605

Bicsák, G., \& Veress, A. (2017). New adaptation of actuator disc method for aircraft propeller CFD analyses. Acta Polytechnica Hungarica, 14(6), 95-114.

Cwojdziński, L., \& Adamski, M. (2014). Power units and power supply systems in UAV. Aviation, 18(1), 1-8. https://doi.org/10.3846/16487788.2014.865938

Davies, C., Holt, J. E., \& Griffin, I. A. (2006). Benefits of inverse model control of Rolls-Royce civil gas turbines. In Proceedings of International Control Conference 2006. Glasgow, UK. ISBN 0947649549.

Dinc, A. (2016). Optimization of a turboprop UAV for maximum loiter and specific power using genetic algorithm. International Journal of Turbo and Jet Engines, 33(3), 265-273. https://doi.org/10.1515/tjj-2015-0030

do Nascimento, M. A. R., de Oliveira Rodrigues, L., dos Santos, E. C., Gomes, E. E. B., Dias, F. L. G., Velásques, E. I. G., \& Carrillo, R. A. M. (2013). Micro gas turbine engine: A review. In Benini, E. (Ed.), Progress in Gas Turbine Performance. Intech Open, 2, ch. 5, 107-141. https://doi.org/10.5772/54444

Dutczak, J. (2016). Micro turbine engines for drones propulsion. In Proceedings of the 2016 IOP Conference Series: Materials Science and Engineering, 148, 012063. https://doi.org/10.1088/1757-899X/148/1/012063

Elkhateeb, N. A., Badr, R. I., \& Abouelsoud, A. A. (2014). Constrained linear state feedback controller for a low-power gas turbine model. Journal of Control Engineering and Technology, 4(1), 66-75.

Garrett turbocharger compressor maps. (n.d.). Retrieved from http://turbocharged.com/catalog/compmaps/fig1.html

Garrett turbocharger turbine maps. (n.d.). Retrieved from http:// www.turbobygarrett.com/turbobygarrett/compressormaps

Katolicky, Z., Bušov, B., \& Bartlova, M. (2014). Turbojet engine innovation and TRIZ. In Proceedings of the $16^{\text {th }}$ International Conference on Mechatronics (pp. 16-23). Brno, Czech Republic. https://doi.org/10.1109/MECHATRONIKA.2014.7018230

Kuz'michev, V. S., Tkachenko, A. Y., Filinov, E. P., Krupenich, I. N., \& Ostapyuk, Y. A. (2017). Optimization of working process parameters of small-scale turbojet for unmanned aircraft. In Proceedings of the 2017 International Conference on Mechanical, System and Control Engineering (ICMSC) (pp. 125-129). St. Petersburg, Russia. https://doi.org/10.1109/ICMSC.2017.7959456

Nyulászi, L., Andoga, R., Butka, P., Főző, L., Kovacs, R., \& Moravec, T. (2018). Fault detection and isolation of an aircraft turbojet engine using a multi-sensor network and multiple model approach. Acta Polytechnica Hungarica, 15(2), 189209. https://doi.org/10.12700/APH.15.1.2018.2.10

Seo, J. M., Lim, H. S., Park, J. Y., Park, M. R., \& Choi, B. S. (2017). Development and experimental investigation of a $500-\mathrm{W}$ 
class ultra-micro gas turbine power generator. Journal of Energy, 124, 9-18. https://doi.org/10.1016/j.energy.2017.02.012

Tavakolpour-Saleh, A. R., Nasib, S. A. R., Sepasyan, A., \& Hashemi, S. M. (2015). Parametric and nonparametric system identification of an experimental turbojet engine. Aerospace Science and Technology, 43, 21-29. https://doi.org/10.1016/j.ast.2015.02.013

Tudosie, A. (2012). Aircraft single-spool single-jet engine with variable area exhaust nozzle. In Proceedings of the International Conference on Applied and Theoretical Electricity (ICATE) (pp. 141-144). Craiova, Romania. https://doi.org/10.1109/ICATE.2012.6403465

Williams, R. L., \& Lawrence, D. A. (2007). Linear state-space control systems. John Wiley and Sons, Hoboken, N.J. https://doi.org/10.1002/9780470117873

\section{Notations}

\section{Variables and functions}

$a_{1}-a_{4}-$ coefficients for compressor dimensionless mass flow rate;

A - system matrix;

$b_{1}-b_{4}-$ coefficients for compressor isentropic efficiency;

B - input matrix;

$c_{1}-c_{4}-$ coefficients for turbine dimensionless mass flow rate;

C - output matrix;

$c_{p a}-$ isobaric specific heat of pure air;

$c_{p g}$ - isobaric specific heat of exhaust gasses;

$c_{v}$ - isochoric specific heat;

$F_{T}$ - thrust

$H_{a}$ - net calorific value of fuel;

$i_{2}^{*}$ - compressor outlet total enthalpy;

$i_{3}{ }^{*}$ - turbine inlet stagnation enthalpy;

$K_{T}$ - turbine geometry constant;

$m_{C C}-$ gas mass in combustion chamber;

$\dot{m}_{2}$ - compressor discharge air mass flow rate;

$\dot{m}_{3}$ - turbine inlet combustion gas mass flow rate;

$\dot{m}_{\text {fuel }}$ - fuel mass flow rate;

$n$ - rotor speed;

$p_{1}^{*}$ - compressor inlet total pressure;

$p_{2}^{*}$ - compressor discharge stagnation pressure; $p_{3}{ }^{*}$ - turbine inlet total pressure;

$p_{5}{ }^{*}$ - total pressure at engine exhaust;

$P_{C}$ - compressor power;

$P_{T}$ - turbine power;

$q\left(\lambda_{1}\right)$ - dimensionless mass flow rate (gas dynamic function) at compressor inlet;

$q\left(\lambda_{3}\right)$ - dimensionless mass flow rate at turbine inlet;

$R$ - specific gas constant;

$R_{g}$ - specific gas constant for combustion gasses;

$\sigma_{C C}$ - total pressure recovery factor of combustion chamber;

$\sigma_{D}$ - total pressure recovery factor of diffuser downstream of turbine;

$T_{1}^{*}$ - compressor inlet total temperature;

$T_{3}{ }^{*}$ - turbine inlet total temperature;

$u$ - input vector;

$V_{C C}$ - volume of combustion chamber;

$x$ - state vector;

$y$ - output vector;

$\beta$ - gas dynamic constant;

$\delta$ - relative error;

$\eta_{C}-$ compressor isentropic efficiency;

$\eta_{C C}-$ combustion efficiency;

$\eta_{N}$ - nozzle efficiency;

$\eta_{m}-$ mechanical efficiency;

$\kappa$ - adiabatic exponent;

$\kappa_{a}$ - adiabatic exponent of pure air;

$\kappa_{g}$ - adiabatic exponent of exhaust gasses;

$\pi_{C}$ - compressor pressure ratio;

$\pi_{T}$ - turbine pressure ratio;

$\sigma_{C C}$ - total pressure recovery factor of combustion chamber;

$\sigma_{D}$ - total pressure recovery factor of diffuser (downstream of turbine);

$\Theta$ - rotor inertia;

\section{Abbreviations}

EPR - Engine Pressure Ratio

LQI - Linear Quadratic Integrating

MSE - Mean Squared Error

TPR - Turbofan Power Ratio 